\title{
Concepções de policiais sobre crianças em situação de rua: um estudo sobre preconceito
}

\author{
Elder Cerqueira-Santos ${ }^{1}$ \\ Sílvia H. Koller \\ Christian Pily \\ Daniela D. Dias \\ Flávia Wagner
}

\section{Resumo}

O objetivo deste estudo foi investigar a concepção que policiais militares têm das crianças em situação de rua. Pela técnica da inserção ecológica, doze policiais homens foram selecionados ao acaso e entrevistados nas ruas perante um roteiro pré-estabelecido. Foi realizada uma análise qualitativa do conteúdo das entrevistas e de diários de campo dos pesquisadores. Os critérios utilizados pelos policiais para definir a criança em situação de rua foram a aparência, as atividades desenvolvidas na rua, o comportamento, a freqüência com que as crianças estão na rua, o local de permanência e a relação da criança com a família. Para todos os critérios houve uma tendência à valoração negativa, no entanto, percebeu-se uma relativização do conceito criado. O estudo destacou a importância da qualificação profissional no enfrentamento deste problema social, sobretudo num caráter educativo que revele melhor a dinâmica de vida das crianças em situação de rua.
\end{abstract}

Palavras-chave: Polícia; Preconceito; Crianças de rua.

\section{Police officers' conceptions about street children: A study about prejudice}

\begin{abstract}
This study aims to investigate police officers conception of street children. The ecological engagement was used to interview twenty male police officers, selected by chance, on the streets. A qualitative analyses was based on the interviews and the researchers journal notes. The main criteria that the police officers used to define street children was the children appearance, their activities on the streets, their behaviors, the frequency that they stay on the streets, the place where they stay and their family contact. These criteria show that they attributed negative value to children. In the other hand, some relativism was perceived in their concept of street child. This study stressed the importance of the professional qualification to fight against this social problem, mainly through educative work, which will allow the understanding of the children street life dynamics.
\end{abstract}

Keywords: Police; Prejudice; Street children.

\section{Introdução}

Este estudo visou investigar a opinião de policiais militares de Porto Alegre sobre crianças em situação de rua. Partindo do pressuposto de que a forma como se percebe determinado grupo influencia diretamente a atuação em relação ao mesmo, buscou-se explorar a concepção que esses profissionais têm sobre essas crianças que povoam o seu cotidiano de trabalho na rua. Com base em uma série de relatos de crianças coletados ao longo de dez anos de pesquisas do Centro de Estudos Psicológicos sobre Meninos e Meninas de Rua (Alves, 1998; Cerqueira-Santos, 2004; Koller \& Hutz, 1996; Neiva-Silva \& Koller, 2002; Santana, 2003, entre outros), percebeu-se o papel dos policiais na vida de crianças em situação de rua, ora descrito como fortemente protetivo, ora altamente vulnerabilizante.
Assim, surgiu a necessidade de investigar o "outro lado da história" e dar voz aos policiais para entender como estes percebem as crianças em situação de rua.

Muitas crianças contam histórias sobre o apoio recebido na rua de pessoas em geral e de policiais. Há muitos que indicam o policial como amigo, como "tio" e como pessoas com quem sabem que podem contar nas horas de necessidade e de busca de companhia. No entanto, há também o relato comum de palavras e atitudes carregados de preconceito, incluindo, muitas vezes, ações policiais que levam à limitação de espaço e imposição de fronteiras às crianças. Não raramente são ouvidos comentários como: - "Eu não sou ladrão só por viver na rua!", ou - "Só porque eu quis entrar na loja, e estava mal vestida, o policial me barrou." Tais relatos revelam o preconceito embutido nas experiências vividas que, segundo Lacerda, Pereira e Camino (2002), pode ser

\footnotetext{
${ }^{1}$ Endereço para correspondência:

CEP-RUA/UFRGS - Instituto de Psicologia - Rua Ramiro Barcelos - 2.600/104 - 90035-003 - Porto Alegre-RS

Fone: (51) 33165150 - Fax: (51) 32410074

E-mail: cep_rua@ufrgs.br.
} 
definido como uma forma de relação intergrupal, pela qual atitudes negativas são expressas, depreciando o outro mediante comportamentos hostis e discriminatórios. Tal preconceito é dirigido a um membro de um grupo, neste caso a criança em situação de rua, simplesmente por mostrar visivelmente pertencer a esse grupo. Portanto, fica evidente que viver na rua, estar desacompanhada, em horas que uma criança não deveria estar, desempenhar atividades e apresentar aparência de abandono são estereótipos que consolidam atitudes preconceituosas (Neiva-Silva \& Koller, 2002).

O preconceito e a discriminação, segundo Bandeira e Batista (2002), estão duplamente associados à emergência das diferenças entre as pessoas e os grupos: seja pela afirmação e manipulação da condição da diferença, seja por sua insistente negação ou dissimulação. Em ambos os casos, o nãoreconhecimento ou a falta de respeito às diferenças se fazem presentes, criando novos padrões de violência. Dessa forma, o preconceito pode instalar-se como um dos meios de geração da violência, em vários níveis. $\mathrm{O}$ preconceito implica, portanto, uma relação social, fazendo-se perceber no modo como se dá a relação com a diferença.

A analogia entre preconceito e criança em situação de rua, portanto, pode ser estabelecida com base na construção do conceito de "criança de rua". Em todo o mundo existem muitas crianças que são assim definidas porque vivem ou passam parte de seu tempo na rua. Porém, ainda não foi definido um conceito único que seja adotado pela ciência para designá-las. A própria literatura científica tem dificuldade de conceituar essa população, embora existam várias sugestões metodológicas (Martins, 1996a). De fato, esta é uma questão difícil e alvo de preocupação da literatura científica, especialmente relacionada ao estabelecimento de rigor metodológico em pesquisas sobre o tema (Neiva-Silva \& Koller, 2002). Do ponto de vista do senso comum, no entanto, há uma visão estereotipada dessas crianças, que são tratadas como marginais $e$ delinqüientes ou como coitadinhas (Aptekar, 1996). Contudo, pesquisas mostram que elas possuem traços sadios de personalidade e que, apesar da adversidade da situação em que vivem, são crianças em desenvolvimento (Koller \& Hutz, 1996).

A descrição dada a esta população vem sofrendo modificações desde a sua criação. A primeira definição que aparece na literatura é a das Nações Unidas (Martins, 1996a):

Uma criança de rua é qualquer menino ou menina que não alcançou a idade adulta e para quem a rua (no senso mais amplo da palavra, incluindo casas abandonadas, terrenos baldios etc.) tornou-se sua habitual fonte de vida e que é inadequadamente protegida, supervisionada ou orientada por adultos responsáveis. (p. 36)

A partir de 1986, a UNICEF passou a usar uma nova definição, composta de três itens, utilizando como indicador base o contato familiar (Martins, 1996a): 1) "candidatos a rua": crianças que vivem com suas famílias, mas trabalham na rua; 2) "crianças na rua": crianças cujo suporte familiar é "inadequado e/ou esporádico"; e, 3) "crianças de rua": crianças sem suporte familiar. Em 1992, a Secretaria da Criança de São Paulo definiu essa população como: "crianças e adolescentes para quem a rua é o espaço principal ou secundário do cotidiano na garantia de subsistência e do lazer ou de ambos simultaneamente" (Martins,1996b; Rosemberg, 1996). Alguns estudos agrupam essa população em categorias para melhor explicar o observado nas ruas. Por exemplo, Lusk (1992) categoriza em: 1) crianças que trabalham na rua, mas têm uma base familiar; 2) crianças que são independentes (diminuindo os laços com a família); 3) crianças de famílias de rua; e, 4) crianças de rua que perderam o contato com a família. Atualmente têm-se utilizado alguns indicadores para definir crianças em situação de rua (Neiva-Silva \& Koller, 2002), como: aparência de abandono, relações familiares instáveis, atividades diurnas (trabalho e escola), eventos de risco (uso de drogas, exploração, abuso, roubo etc.) e lugar onde dormem e obtém alimentação. Paludo e Koller (2004) sugerem que seja também observado o fator tempo nesta classificação, uma vez que em certos horários do dia não é apropriado que uma criança esteja na rua sozinha, o que pode configurar um indicador de situação de rua. Há uma preocupação por parte dos pesquisadores em encontrar uma definição clara para o conceito de criança em situação de rua para seus estudos acadêmicos, no entanto, pela revisão da literatura, é detectada a ausência de estudos que mostrem a definição utilizada pelos profissionais que atuam junto a essas crianças, entre eles os policiais militares.

Martins (1996b), partindo da idéia de que as definições dadas às crianças influenciam diretamente nas práticas sobre estas, apresenta quatro abordagens de intervenção comumente encontradas na prática profissional - correcional, reabilitadora, educativa e preventiva. $\mathrm{O}$ autor propõe, então, refletir sobre quais destas concepções estão embasando tais práticas. A abordagem correcional ou institucionalizadora, assim como a de reabilitação, pressupõe que a criança é um

Psico-USF, v. 11, n. 2, p. 249-256, jul./ de₹. 2006 
delinqüente que deve ser recuperado. As abordagens da educação de rua e a preventiva pressupõem que a criança é reflexo de problemas estruturais da sociedade, portanto estaria mais no papel de vitimizada. Ou seja, mesmo que não seja explícita, existe uma ideologia ou um pré-conceito sobre o fenômeno por trás de cada tipo de prática.

A Abordagem Ecológica do Desenvolvimento Humano permite uma análise sobre a relação do pré-conceito e sua possível ação sobre a prática profissional (Bronfenbrenner, 1979/1996, 1999, 2004; Bronfenbrenner \& Morris, 1998; Bronfenbrenner \& Evans, 2000). Segundo esta abordagem, os processos proximais que geram desenvolvimento das pessoas precisam ser investigados nos ambientes reais, nos quais as pessoas interagem. Além da contextualização, a compreensão temporal do fenômeno também se torna fundamental para o entendimento dos dados. Nesse sentido, a inserção ecológica dos pesquisadores (Cecconello \& Koller, 2004) no microssistema da rua possibilita maior validade ecológica dos processos proximais vividos pelos policiais e como estes interagem com as pessoas e símbolos presentes em seu contexto.

Tendo em vista esses aspectos, este estudo visou investigar a opinião de policiais militares de Porto Alegre sobre crianças em situação de rua, buscando-se identificar fatores de risco ou de proteção na forma como atuam em relação a essas crianças.

\section{Método}

\section{Participantes}

A amostra foi composta por 12 policias da Brigada Militar de Porto Alegre, sendo todos do sexo masculino, com idades entre 30 e 40 anos, detentores das patentes de cabo e soldado, com mínimo de um ano de experiência. Foram selecionados ao acaso, em dias e horários variados, entre aqueles que trabalham na região central da cidade. Ou seja, foi abordado qualquer policial que se encontrava nas ruas do centro da cidade nos horários de coleta de dados. Todos os policiais entrevistados mostraram-se disponíveis para conversar. Os critérios de inclusão foram a presença na rua e a disponibilidade em participar da pesquisa. Todos tinham escolaridade de nível médio e dois estavam cursando o nível superior. Todos relataram ter experiências com crianças em suas famílias, sejam com filhos, sobrinhos ou irmãos e, mesmo, com crianças em situação de rua.

\section{Instrumentos e procedimentos}

Foi realizada uma entrevista aberta iniciada pela questão: - "Quem é a criança em situação de rua?" Conforme a resposta dada, era iniciado um diálogo com o policial, orientado por um roteiro preestabelecido, baseado em tópicos como: preconceito, violência, uso de drogas, familia, educação de crianças em situação de rua etc. Para cada tópico foi realizada, no mínimo, uma pergunta ampla com a possibilidade de réplica e tréplica para um mesmo tema.

$\mathrm{Na}$ etapa prévia à coleta de dados, houve preparação teórico-metodológica dos entrevistadores, em razão da exigência de domínio para a utilização do instrumento escolhido. $\mathrm{O}$ roteiro de entrevista foi previamente discutido, memorizado e testado, o que permitiu um maior aproveitamento do tempo disponível para coleta de informações. Os participantes foram abordados nas ruas centrais da cidade, quando estavam em serviço, e solicitados a participar do estudo por uma dupla de pesquisadores. As entrevistas foram realizadas no próprio local, de pé e tiveram duração variável, com média de 15 minutos, a depender da colaboração dos participantes e das condições do local, como interferências externas, ruído de trânsito, solicitações de outras pessoas etc. Ao final da entrevista, foi solicitada a anuência verbal para a utilização do conteúdo da "conversa" para o estudo. Os pesquisadores, então, redigiam imediatamente um diário de campo, registrando, quando possível, algumas falas literais dos entrevistados.

\section{Resultados e discussão}

As respostas às entrevistas foram submetidas a uma análise de seu conteúdo, assim como os diários de campo (Bardin, 1977/1979). Foi utilizada a técnica de análise temática, baseada nas transcrições das entrevistas realizadas. Todas as categorias foram criadas a posteriori.

Uma primeira constatação da equipe foi a de que as respostas tendiam a ser diretas e evasivas. Algumas sessões de coleta de dados foram mais breves, porque os policiais justificaram estar em serviço. No entanto, observações complementares revelaram uma certa resistência à participação em uma pesquisa sobre este tópico por parte dos participantes. Por isso, o uso do processo de inserção ecológica garantiu o sucesso da coleta de dados (Cecconello \& Koller, 2004), pois a imersão no campo da pesquisa permitiu, pela observação, conversas informais e outras atividades mais complexas, uma melhor compreensão dos fenômenos investigados. A aproximação com os policiais demandou um aprendizado, por parte dos pesquisadores, que resultou num gradativo aumento da quantidade de dados coletados, conseqüência do aumento da duração das entrevistas e das possibilidades de obtenção de dados.

\section{Conceito de criança de rua pelos policiais}

Os critérios utilizados pelos policiais para definir a criança em situação de rua foram a aparência, as atividades desenvolvidas na rua, o comportamento, a 
freqüência com que as crianças estão na rua, o local de permanência e a relação da criança com a família. Estes são definidos como:

- Aparência: aspectos exteriores mencionados em relação à vestimenta e/ou à higiene das crianças;

- Atividade/comportamento: menção às atividades desenvolvidas pela criança na rua, como pedir, roubar e cheirar loló etc., e/ou comportamento ser violento, agressivo etc.;

- Freqüência/local: definição relacionada ao espaço ocupado na rua e o tempo de utilização deste;

- Relação com a família: presença/ausência de familiares ou adultos cuidadores junto às crianças.

A aparência foi destacada como um dos principais e primeiros aspectos para identificação da criança em situação de rua. De uma forma geral, as crianças foram conceituadas como mal vestidas e sujas, como fica exemplificado nestes trechos: "As crianças de rua são sujas e mal vestidas"; "Nós identificamos as crianças principalmente pelas vestes. Elas são mal vestidas."

Tal visão contrasta a aparência dessas crianças com aquelas que não se encontram na mesma situação. Os policiais, em geral, comparavam as crianças em situação de rua com seus filhos e parentes. Apesar dessa caracterização, houve uma certa relativização por parte de alguns, o que demonstra que esse não é um critério estático e único. A fala de um dos policiais entrevistados ilustra bem isso: "Quanto à vestimenta, não que toda criança que esteja mal vestida seja de rua, mas com outros fatores dá para perceber." Para NeivaSilva e Koller (2002), a aparência é realmente um dos critérios mais freqüentemente usados por pesquisadores e profissionais para identificar as crianças em situação de rua. A aparência é tão importante que, quando elas estão limpas e bem vestidas, têm livre acesso a lugares públicos e até privados, como supermercados e shopping centers. Um policial destacou tal importância dizendo: "Quando as crianças de rua estão com uma roupinha mais limpa, elas entram até no supermercado."

Parece haver uma compreensão por parte dos policiais, mesmo que seja mínima, de que algumas crianças em situação de rua precisam estar bem vestidas para "sobreviver", pois têm que trabalhar e, portanto, algumas não podem estar sujas. Neiva-Silva e Koller (2002) alertam para o fato de que podem ser encontrados crianças e adolescentes que não se ajustam a uma descrição ruim quanto à aparência. É comum encontrar crianças bem vestidas, pois a atividade por elas desempenhada pode requisitar que tenha mais cuidado com sua aparência e higiene. Este é certamente o caso daquelas que vendem produtos comestíveis. Outro aspecto é o envolvimento com algumas atividades lucrativas, que oferecem recursos para que comprem roupas de grifes, realizando desejos de consumo comuns a qualquer adolescente.

A aparência, portanto, está conectada com a atividade e o comportamento na rua. Esses foram os outros dois aspectos mais citados pelos policiais como importantes para identificação das crianças em situação de rua. De uma maneira geral, essas crianças foram caracterizadas pelos policiais como desempenhando atividades ilícitas (não aceitas socialmente) ou comportamentos socialmente reprováveis (como mendigar, ser violentos e furtar). A mendicância, o roubo e o uso de drogas (principalmente loló) foram citados em diversos depoimentos. Houve, também, uma tendência, por parte dos policiais, de caracterizar as crianças como tendo comportamentos violentos e rebeldes. Expressaram, também, o uso de um vocabulário agressivo, pela utilização de palavrões. Tais impressões são evidenciadas nessas falas: "As crianças de rua ficam pedindo ou ligadas para roubar"; "As crianças de rua ficam pedindo, roubando"; "As crianças de rua ficam cheirando loló"; "As crianças de rua podem ser perigosas, elas podem querer te roubar"; "As crianças de rua são mais rebeldes, não respeitam principalmente nós, policiais.”

No entanto, há opiniões divergentes entre os policiais. Apesar de ser a tendência geral, houve policiais que caracterizavam essas crianças de uma forma diferente e reconheciam uma certa ingenuidade em algumas delas, o que nem sempre as colocava na posição de vitimizadas, mas reconhecia uma porção de vítima. Estas posições são expressas: "Tem uns que são infratores e outros não. A maioria não é infratora"; "As crianças de rua não são violentas, elas não vão chutar vocês."

Um fato que chamou a atenção dos pesquisadores foi que não foram citadas atividades lícitas como trabalhar, por exemplo. Aliás, percebeu-se que o trabalho das crianças (guardar carros, rodar calotas, malabarismo), quando citado nas entrevistas, não foi considerado uma atividade séria, tendo a conotação de que isso é pedir esmolas: "Que trabalho, que nada. Quem trabalha somos nós. É muito fácil dizer que guarda carros e ficar pedindo dinheiro."

Esses dados contrastam com depoimentos obtidos das próprias crianças (Cerqueira-Santos \& Koller, 2003, 2004; Neiva-Silva, 2003), nos quais as suas atividades eram valorizadas e reconhecidas como forma digna de obtenção de dinheiro, seja para o sustento pessoal ou para o auxílio da família. Neste ponto, gerase uma questão complicada, pois, enquanto o trabalho parece ser um fator de autovalorização para as crianças, que poderia até funcionar como um estímulo ao

Psico-USF, v. 11, n. 2, p. 249-256, jul./ dez. 2006 
abandono de atividades ilícitas, é uma atividade desvalorizada e pouco aparente por aqueles que estão no mesmo contexto.

Os dados obtidos neste estudo propõem uma análise da função de idéias preconceituosas na prática dos policiais que lidam com as crianças em situação de rua. Semanticamente, o preconceito significa "fazer um julgamento prematuro, inadequado sobre a coisa em questão" (Ferreira, 2004). Ao produzir a identidade das crianças de rua, os policiais criam sentimentos de pertença e de estranhamento, o que gera uma dinâmica de inclusões e exclusões com base em semelhanças e diferenças. Essas, muitas vezes, não indicam apenas diferenças e singularidades, mas refletem relações hierárquicas e poderes de raiz histórica, que demandam para si a definição do que é bom ou ruim. Ou seja, quando os policiais circunscrevem o grupo de crianças em situação de rua como diferente do grupo formado por todas as outras crianças, a condição de ser criança passa a ser minimizada, ficando estas caracterizadas pelo "grupo da rua" em contraste ao "grupo que tem casa". O relato a seguir confirma essa idéia, na opinião de um policial: "Existem dois grupos de crianças: as que roubam e as que pedem. Meu filhos, por exemplo, são crianças que pedem. As crianças de rua roubam!”. Fica evidente, nessa fala, a definição hierárquica apresentada por Bandeira e Batista (2002) como resultado do preconceito. A valoração do que é bom e ruim parece ser uma conseqüência natural no processo de divisão dos grupos.

O preconceito expresso pelos policiais pode levar a erros graves na sua atuação. Machado e Noronha (2002) constataram, em um estudo sobre a percepção de pessoas de classes populares sobre a violência policial, que a aparência pessoal - raça, modo de vestir, qualidade das roupas - é determinante na relação entre os policiais e os moradores do local onde foi realizado o estudo. Os participantes do estudo relatam que aqueles de quem os policiais suspeitam e a quem muitas vezes agridem são negros e pobres. Nos dados obtidos neste estudo não houve menção à raça das crianças, talvez porque muitos dos policiais também pertenciam a mesma raça.

Fisher, Wallace e Fenton (2000) realizaram um estudo para investigar a idéia e os sentimentos despertados pela percepção de discriminação em adolescentes de diferentes etnias dos Estados Unidos. Em relação à polícia e aos guardas de lojas, adolescentes mais velhos, negros e hispânicos relataram, em número mais expressivo, sentimento de angústia associado à percepção de preconceito por parte desses profissionais. Muitos desses adolescentes acreditam que a raça/etnia leva as pessoas a perceberem-nos como perigosos, o

Psico-USF, v. 11, n. 2, p. 249-256, jul./ de₹. 2006 que determina a implicância que sentem por parte de policiais e guardas. Os autores ressaltam a escassez de estudos sobre o impacto da discriminação por parte de instituições como a polícia e as implicações desse fenômeno no desenvolvimento dos adolescentes.

A formação de um preconceito está baseada na percepção de uma diferença inscrita no corpo. Os achados deste estudo demonstram que uma das principais formas pelas quais os policiais entrevistados reconhecem crianças em situação de rua é, justamente, por meio de sua aparência. A atribuição de valores negativos às diferenças percebidas é um reflexo de relações de poder definidas historicamente e determina a forma como será construída a relação entre as crianças em situação de rua e os policiais. Talvez dessa relação decorra a dificuldade de perceber este fenômeno: crianças nas ruas - como um reflexo da estrutura social, pré-julgando-os apenas pela apreensão de características/percepções imediatas.

Da mesma forma, essa interação é bidirecional. A maneira pela qual as crianças em situação de rua vêem os policiais também é permeada pela construção dessa relação. Em estudo realizado com as crianças dessa população, Cerqueira-Santos e Koller (2003, 2004) destacam a distinção de papel que a criança faz quanto ao policial e aos pesquisadores. As crianças do estudo demonstravam medo dos policiais e confiavam nos pesquisadores (pessoas estranhas). Enquanto uma criança em situações típicas de desenvolvimento tenderia a "fugir" de estranhos e sentir-se protegida pela polícia, as crianças, em sua maioria, entendem a figura do policial como um fator de risco e fogem daquilo que, oficialmente, deveria protegê-las.

Para Bandeira e Batista (2002), uma sociedade que prega a construção diferenciada e não-plural de seus membros, como signo do preconceito, que admite o acesso particularizado de alguns, seja aos bens materiais, seja aos bens culturais, que dá valoração positiva à desigualdade substantiva de seus membros, está fadada à instauração da violência nas suas variantes materiais e simbólicas. Uma visão maniqueísta do mundo não vale para entender qualquer tipo de situação humana. Dessa forma, julgar o grupo de crianças em situação de rua é, antes de qualquer coisa, um ato de preconceito e resulta em violência, ainda que simbólica. De modo geral, os policiais não conhecem detalhes sobre a vida dessas crianças e mantêm uma relação principalmente profissional, mostrando distanciamento dos aspectos afetivos e familiares que circundam as suas vidas e a condição de estarem na rua. No entanto, é possível perceber abertura para o estabelecimento de uma relação que revele a criança como um ser humano em desenvolvimento. Os resultados deste estudo apontam 
que nem todos os policiais agem de forma maniqueísta. Foi possível perceber uma relativização no discurso de alguns entrevistados, tentando analisar as questões sociais e familiares que estão por trás da criança em situação de rua. Nesse sentido, os policiais com maior nível de escolaridade tiveram um discurso mais ponderado e tolerante. Não foi o objetivo deste estudo investigar essa variável, mas tal dado é de fundamental importância para a realização de novas investigações e possíveis intervenções. A informação parece ser uma poderosa arma contra o "pré-conceito" e, conseqüentemente, contra a violência.

\section{Considerações}

O entendimento das relações estabelecidas entre profissionais e crianças em situação de rua é fundamental na colaboração entre a pesquisa científica e as iniciativas de intervenções junto a essa população. Diante do escândalo social que esta questão provoca, foram presenciadas várias tentativas de amenizar o problema das crianças em situação de rua. No entanto, parece notável a falta de compreensão do caráter sistêmico que precede e mantém este problema. Esta carência aparece, não somente nos tópicos apontados por este estudo, mas também na compreensão básica da dinâmica família-criança-rua-instituições.

Este estudo tentou apontar mais uma faceta da ampla dinâmica da vida nas ruas. A Abordagem Ecológica do Desenvolvimento Humano (Bronfenbrenner, 1979/1996; 1999; 2004; Bronfenbrenner \& Morris, 1998; Bronfenbrenner \& Evans, 2000) mostrou-se um aporte teórico-metodológico de sucesso neste tipo de investigação, uma vez que permitiu analisar o fenômeno além do "aqui e agora", questionando os variados pontos de vista e entendendo as relações culturais e sócio-históricas envolvidas na construção do problema. A inserção ecológica no espaço da rua garantiu a validade ecológica do estudo, pois as respostas dadas às entrevistas eram evidenciadas no comportamento observado dos participantes.

Ainda do ponto de vista metodológico, o processo de inserção, por exemplo, permitiu analisar alguns dados relacionados à postura dos policiais diante dos diferentes inquisidores. Uma variação na apresentação dos pesquisadores, ora como estudantes da Universidade Federal do Rio Grande do Sul (UFRGS), leva a respostas ainda mais vazias e evasivas. Numa aproximação informal e uma conversa iniciada como cidadãos comuns, curiosos por saber como identificar uma criança de rua, as respostas já foram mais elaboradas e os participantes se mostraram mais disponíveis. Por uma questão ética, a apresentação deu- se como estudantes ávidos por aprender sobre as crianças em situação de rua e sem conhecimentos prévios no assunto. Tal estratégia foi escolhida, pois os policiais davam respostas mais consistentes ao serem colocados num nível superior de conhecimento, como alguém que ensinaria sobre o tema.

Houve, também, limitações deste estudo que podem ser superadas em novas investigações. Não foi possível um maior controle no processo de amostragem, o que reduziu a possibilidade de análises de variáveis como gênero, paternidade/maternidade e, com destaque, escolaridade, que se mostrou uma variável de extrema importância. Além disso, foi impossível fazer gravações das verbalizações dos policiais (por questões éticas). Assim, novas metodologias podem ser aplicadas para a investigação desta questão, com, por exemplo, utilização de técnicas de grupos focais, ou estudos de caráter quantitativo.

Apesar das limitações, os dados aqui apresentados já apontam para a importância do investimento na qualificação dos profissionais que lidam com as crianças em situação de rua para que não se corra o risco de vê-las destituídas do seu maior direito: serem tratadas como crianças. Projetos de intervenção são necessários (como extensões universitárias, iniciativas governamentais etc.) que podem consistir em um dos tantos aspectos que contribuirão para a melhoria da vida das crianças que vivem nas ruas do nosso país.

\section{Referências}

Alves, P. B. (1998). O brinquedo e as atividades cotidianas de crianças em situação de rua (Dissertação de Mestrado). Porto Alegre, RS: Universidade Federal do Rio Grande do Sul - Curso de Pós-Graduação em Psicologia do Desenvolvimento.

Aptekar, L. (1996). Crianças de rua nos países em desenvolvimento: uma revisão de suas condições. Psicologia: Reflexão e Crítica, 9, 153-184.

Bandeira, L. \& Batista, A. S. (2002). Preconceito e discriminação como expressões de violência. Revista de Estudos Femininos [On-line], 10(1). Disponível em: <www.scielo.com.br>. Acesso em: 10.nov.2003

Bardin, L. (1979). Análise de conteúdo (L. A. Reto \& A. Pinheiro, Trad.). São Paulo: Edições 70, Livraria Martins Fontes. (Original publicado em 1977).

Bronfenbrenner, U. (1996). A ecologia do desenvolvimento bumano: experimentos naturais e planejados (M. A. V. Veronese, Trad). Porto Alegre: Artes Médicas. (Original publicado em 1979).

Psico-USF, v. 11, n. 2, p. 249-256, jul./deæ. 2006 
Bronfenbrenner, U. (1999). Environments in developmental perspective: Theoretical and operational models. Em B. L. Friedmann \& T. D. Wacks (Orgs.). Conceptualization and assessment of environment across the life span (pp. 3-30). Washington, DC: American Psychologial Association.

Bronfenbrenner, U. (2004). Making human beings buman: Bioecological perspectives on buman development. New York, NY: Sage Publications, Inc.

Bronfenbrenner, U. \& Morris, P. (1998). The ecology of developmental processes. Em W. Damon (Org.). Handbook of child psychology (v. 1, pp. 993-1027). New York, NY: John Wiley \& Sons.

Bronfenbrenner, U. \& Evans, G. (2000). Developmental science in the $21^{\text {st }}$ century: emerging questions, theoretical models, research designs and empirical findings. Social Development, 9, 115-125.

Cecconello, A. M. \& Koller, S. H. (2004). Inserção ecológica na comunidade: uma proposta metodológica para o estudo de famílias em situação de risco. Psicologia: Reflexão e Crítica, 15(3), 368-389.

Cerqueira-Santos, E. (2004). Um estudo sobre a brincadeira de crianças em situação de rua (Dissertação de Mestrado). Porto Alegre, RS: Universidade Federal do Rio Grande do Sul - Pós-Graduação em Psicologia do Desenvolvimento [On-line]. Disponível em: <www.psicologia.ufrgs.br/cep_rua>.

Cerqueira-Santos, E. \& Koler (2003). Brincando na rua. Em A. M. A. Carvalho, C. M. C. Magalhães, F. A. R. Pontes \& I. D. Bichara (Orgs.). Brincadeira e cultura: viajando pelo Brasil que brinca (v. I., pp. 187-206). São Paulo/SP: Casa do Psicólogo.

Cerqueira-Santos, E. \& Koller, S. H. (2004). O contexto da rua: brincar, trabalhar e estudar. Em S. H. Koller (Org.). Ecologia do desenvolvimento bumano: pesquisa e intervenção no Brasil (pp. 167-188). São Paulo/SP: Casa do Psicólogo.

Ferreira, A. B. H. (2004). Dicionário eletrônico da língua portuguesa. Mídia digital, CD-ROM.

Fisher, C. B., Wallace, S. A. \& Fenton, R. E. (2000). Discrimination distress during adolescence. Journal of Youth and Adolescence, 29(6) [On-line]. Disponível em: $<$ www.periodicoscapes.org.br>. Acesso em: 15.maio. 2004.

Koller, S. H. \& Hutz, C. S. (1996). Meninos e meninas em situação de rua: dinâmica, diversidade e definição. Coletâneas da ANPEPP - Associação Nacional de Pesquisa e Pós-Graduação em Psicologia, 1(12), 11-34.
Lacerda, M., Pereira, C. \& Camino, L. (2002). Um estudo sobre as formas de preconceito contra homossexuais na perspectiva das representações sociais. Psicologia: Reflexão e Crítica, 15(1) [On-line]. Disponível em: $<$ www.scielo.br>. Acesso em: 14.mar.2004.

Lusk, M. (1992). Street children in Rio de Janeiro. International Social Work, 35, 293-305.

Machado, E. P. \& Noronha, C. V. (2002). A polícia dos pobres: violência policial em classes populares urbanas. Sociologias, 7 [On-line]. Disponível em: <www.scielo.br>. Acesso em: 1.abr.2004.

Martins, R. A. (1996a). Criança e adolescentes em situação de rua: definições, evolução e políticas de atendimento. Coletâneas da ANPEPP - Associação Nacional de Pesquisa e Pós-Graduação em Psicologia, 1(12), 35-44.

Martins, R. A. (1996b). Censo de crianças e adolescentes em situação de rua em São José do Rio Preto. Psicologia: Reflexão e Crítica, 9, 101-122.

Neiva-Silva, L. (2003) Expectativas futuras de adolescentes em situação de rua: um estudo autofotográfico (Dissertação de Mestrado). Porto Alegre, RS: Universidade Federal do Rio Grande do Sul - Curso de Pós-Graduação em Psicologia do Desenvolvimento.

Neiva-Silva, L. \& Koller, S. H. (2002). A rua como contexto de desenvolvimento. Em E. R. Lordelo, A. M. A. Carvalho \& S. H. Koller (Orgs.). Infância brasileira e contextos de desenvolvimento (pp. 205-230). São Paulo: Casa do Psicólogo, Salvador: EDUFBA.

Paludo, S. \& Koller, S. H. (2004). Inserção ecológica no espaço da rua. Em S. H. Koller (Org.). Ecologia do desenvolvimento humano: pesquisa e intervenção no Brasil (pp. 219-244). São Paulo/SP: Casa do Psicólogo.

Rosemberg, F. (1996). Estimativa sobre crianças e adolescentes em situação de rua: procedimentos de uma pesquisa. Psicologia: Reflexão e Crítica, 9, 21-58.

Santana, J. P. (2003). Instituições de atendimento a crianças e adolescentes em situação de rua: objetivos atribuídos por seus dirigentes e pelos jovens atendidos (Dissertação de Mestrado). Porto Alegre, RS: Universidade Federal do Rio Grande do Sul - Curso de Pós-Graduação em Psicologia do Desenvolvimento. 
Sobre os autores:

Elder Cerqueira-Santos é psicólogo, mestre e doutorando em Psicologia pela Universidade Federal do Rio Grande do Sul, tendo feito estágio na University of Nebraska, com apoio do CNPq, e membro do Centro de Estudos Psicológicos sobre Meninos e Meninas de Rua (CEP-RUA/UFRGS). Áreas de interesse: desenvolvimento humano em situações atípicas, psicologia positiva, sexualidade e religião.

Sílvia H. Koller é psicóloga, doutora em Educação (PUCRS), pesquisadora do CNPq e professora do Programa de Pós-Graduação em Psicologia da Universidade Federal do Rio Grande do Sul, coordenadora do Centro de Estudos Psicológicos sobre Meninos e Meninas de Rua (CEP-RUA/UFRGS) e presidente da Associação Nacional de Pesquisa e Pós-Graduação em Psicologia. Áreas de interesse: desenvolvimento humano; psicologia positiva; resiliência; famílias, adolescentes e crianças em situação de risco.

Christian Pilz é psicólogo graduado pela Universidade Federal do Rio Grande do Sul, membro do Centro de Estudos Psicológicos sobre Meninos e Meninas de Rua (CEP-RUA/UFRGS).

Daniela D. Dias é psicóloga graduada pela Universidade Federal do Rio Grande do Sul, membro do Centro de Estudos Psicológicos sobre Meninos e Meninas de Rua (CEP-RUA/UFRGS).

Flávia Wagner é psicóloga graduada pela Universidade Federal do Rio Grande do Sul, membro do Centro de Estudos Psicológicos sobre Meninos e Meninas de Rua (CEP-RUA/UFRGS). 